\title{
Risky HIV sexual behaviour and depression among University of Nairobi students
}

\author{
Caleb J Othieno ${ }^{1 *}$, Roselyne Okoth ${ }^{1}$, Karl Peltzer ${ }^{2,3,4}$, Supa Pengpid ${ }^{2,4}$ and Lucas O Malla ${ }^{5}$
}

\begin{abstract}
Background: Prevalence rates of human immunodeficiency virus (HIV) infection among the youth are disproportionately high compared to that of other age groups in Kenya. Poor mental health has been linked to risky HIV behaviour, yet few local studies have explored these aspects. This study sought to determine associations between HIV risky sexual behaviour and depression among undergraduate students at the University of Nairobi.

Method: A random sample of 923 (525 males and 365 females) undergraduate students was interviewed using a questionnaire to record sociodemographic variables and risky sexual behaviour including having multiple sexual partners, inconsistent condom use and engaging in sex after drinking. Depressive symptoms were measured using the Centre for Epidemiological Studies Short Depression Scale (CES-D 10).

Results: The students' mean age was 23 years (s.d.4.0). Overall, $41.33 \%$ of the students scored above the cut-off point of 10 on the CES-D 10 scale, with $35.71 \%$ having moderate symptoms and 5.62\% having severe depressive symptoms. The percentage of those who had ever been diagnosed with sexually transmitted infections (STIs) was 9.71\% (males 8.65\%; females 11.01\%); and for HIV 3.04\% (males 2.02\%; females 4.05\%). Nearly 30\% reported having had multiple partners in the previous 12 months, $27.4 \%$ of the students did not use condoms with sexual partners and $21 \%$ had engaged in sex after drinking within the previous 3 months. In multivariable-bivariate logistic regression, being older, having depressive symptoms, alcohol use/binge drinking, tobacco use, sex after drinking, previous diagnosis of STI, physical abuse, sexual coercion and history of sexual abuse as a child were significantly associated with having multiple partners. Further, younger age, being female, tobacco use and previous diagnosis of STI were significantly associated with inconsistent condom use.
\end{abstract}

Conclusion: The prevalence of HIV rate infection is low compared to the national average but risky sexual behaviour is common among the students and is positively linked to depressive symptoms among other factors. Programmes aimed at HIV prevention should be integrated with mental health interventions.

Keywords: Students, Depression, Risky sexual behaviour, HIV

\section{Background}

Despite reductions in human immunodeficiency virus (HIV) inflection prevalence rates and increased coverage of those who need ARV drugs in sub-Saharan Africa, the numbers of those infected are still quite high in Kenya and recent studies show a need to reduce the prevalence rate further particularly among the youth [1]. Overall, the national HIV prevalence rate is dropping but wide regional variations continue to be seen. For example, Oluoch and his co-workers [2] reported a national

\footnotetext{
* Correspondence: cjothieno@uonbi.ac.ke

${ }^{1}$ Department of Psychiatry, University of Nairobi, P.O. Box 19676, 00202

Nairobi, Kenya

Full list of author information is available at the end of the article
}

average of $5.6 \%$ ranging from $1.2 \%$ in North Eastern Province to $16.1 \%$ in Nyanza Province. Using data from several sources, recent reports give a national prevalence rate of $6 \%$ (5.6\% for males and $7.6 \%$ for females). The range varied from $0.2 \%$ in Wajir in the northern parts to $25.7 \%$ in Homa Bay County around Lake Victoria. Although the HIV prevalence among the youth is $2.7 \%$ for females and $1.7 \%$ for males, the report estimated that young women in the age group 15-24 years account for $21 \%$ of all the new HIV infections in Kenya [3].

The high rates of HIV infection in the youth could be linked to risky sexual behaviour since most of the HIV infections are through heterosexual transmission. For 
example, inconsistent condom use and unprotected sex with multiple partners, both of which are risk factors for HIV, have been reported among university students [4-7]. A study involving 24 countries in sub-Saharan Africa reported that multiple sexual partnerships were more common among urban males and females with higher education [8]. Among university students, the changes in living arrangements and access to information further increase these risks. [5,9]. Since the university population is a vulnerable group with respect to HIV, it is important to determine factors related to the risky behaviours $[5,10,11]$ and to monitor the trends [8].

Depressive symptomatology in youth has been associated with high-risk sexual behaviour such as early sexual debut, higher number of sexual partners and having sex while under influence of alcohol and drugs [12]. Similar findings have been demonstrated in studies done in subSaharan Africa where HIV is endemic in several countries. Youths in Uganda who had high scores on depression were more likely to report having high numbers of sexual partners [13]. In South Africa, there is evidence that depression is linked to risky sexual behaviour. Young men and women were more likely to have experienced intimate partner violence and to have engaged in unprotected sex or to report incorrect condom use [14]. The same study also found that depression could be a marker of increased HIV risk [14]. The same trends have been observed among university students in Ivory Coast where poor mental health including alcohol use and partner violence was found to be associated with HIV risk behaviour [15]. Although studies from other parts of the world have linked poor mental health to risky sexual behaviour, relatively few studies have been done in Kenya on adolescents and youth mental health. This study, therefore, aims to provide more data on the links between depression and HIV risky behaviour.

\section{Objective}

The objectives of this study were to describe the HIV risky sexual behaviours in relation to depressive symptoms and other sociodemographic variables among undergraduate students at the University of Nairobi in Kenya.

\section{Methods}

\section{Study population}

We obtained permission from the Kenyatta National Hospital and the University of Nairobi Ethics and Research Committee. University of Nairobi is the largest of the seven public universities in Kenya. It has six colleges; College of Architecture and Engineering (Main Campus), College of Humanities and Social Sciences (Main Campus), College of Health Sciences (Kenyatta National Hospital), College of Education and External Studies
(Kikuyu Campus and Kenya Science Campus), College of Agriculture and Veterinary Sciences (Upper Kabete Campus) and the College of Biological and Physical Sciences (Chiromo Campus). The research targeted the University of Nairobi students. The total student population in the University of Nairobi is 36,991 (22,734 males and 14,257 females) [16].

\section{Sampling design}

From the total registered students in the University of Nairobi, each of the six colleges participated in the study in order to achieve representativeness and to increase statistical power. Proportional stratified sampling was used to ensure that the colleges forming different student subpopulations were represented in the sample in same proportions as the population. The sampling process proceeded in two steps. In the first stage, the number of participants to be obtained from each college was determined using calculations based on probability proportional to size. Next, a sampling frame containing a list of all students was compiled from each college. In the second step, a simple random sample was selected within each college using computer-generated random numbers and the available sampling frame.

\section{Measurement of study variables}

We administered a purpose-designed questionnaire to record sociodemographic data including age, sex year of study, socioeconomic status and performance in studies.

Questions on risky sexual behaviour enquired on having multiple sexual partners, inconsistent condom in past 3 months, sex after drinking alcohol, age at first pregnancy/made someone pregnant and past history of sexually transmitted infection.

\section{Depression}

The Centre for Epidemiological Studies Short Depression Scale (CES-D 10) consists of ten questions. It has been used in other parts of sub-Saharan Africa. We used a cut-off point of $\geq 10$. Those who had a score of $0-9$ were classified as having a mild level of depressive symptoms, $10-14$ as moderate depressive symptoms and $\geq 15$ representing severe depressive symptoms. [17-19]. Binge drinking was defined as having more than four or five drinks at a sitting.

\section{HIV risk behaviour}

In terms of HIV risk behaviour, university students were asked, "During the past 12 months how many sexual partners did you have?" "During the past 3 months did you use a condom with your primary partner?" (Response options ranged from $1=$ never to $5=$ every time; inconsistent condom use was defined as not having used a condom every time in the past 3 months). Further, 
students were asked if they had had sex after drinking alcohol in the past 3 months, with the response option, "yes" or "no".

STIs and HIV status: STIs status was assessed with the question, "Have you ever been diagnosed with a sexually transmitted infection?" and HIV status, "Have you ever been diagnosed HIV positive?

\section{Handling of survey non response and missing data}

The response rate was about $70 \%$. To achieve this, extensive awareness of the research was done and this included visits of lecture halls, by research assistants, to educate students on the benefits of the study and also the use of study introductory letter on every questionnaire. Research assistants traced the selected students through the chairmen of their departments where they obtained their contacts. Thereafter, they rung the students to introduce the study and arrange a meeting. Those who were unreachable on phone were traced through their colleagues and their lecture halls. All the respondents filled in a pencil-paper-based questionnaire. All missing data were assumed to be at random.

\section{Statistical analysis}

Results of sociodemographic factors were presented using frequencies and proportions, with their distributions examined separately for males and females. Also, the prevalence of depressive symptoms was presented using proportions, and association between depressive symptoms and potential predictors was investigated using chi-square test. On the other hand, a bivariate logistic regression was fitted to determine the associations between risky sexual behaviour, defined by inconsistent condom use and multiple sexual partners, and potential mental health covariates. Variable selection proceeded as follows; first, unadjusted bivariate model was fitted for each covariate. All covariates that were statistically significant $(P$ value $<0.05)$ were then included in a multivariable-bivariate model. In the study design, sampling was clustered within colleges and college membership included as a fixed effect in the final bivariate model. Twelve respondents, who were married and did not use condoms with partners, were excluded in bivariate analyses.

\section{Software}

Exploratory analyses, calculation of frequencies and proportions were done using IBM SPSS (version 22.0) and bivariate logistic regression fitted using the Zelig package in $\mathrm{R}$ version 3.0.2.

\section{Results}

The sociodemographic characteristics of the study sample are shown in Table 1. We obtained data from 923 students
(525 males and 365 females). The mean age was 23 years (s.d.4.0). Two-thirds resided within the campus. Ninety percent were single. More females (15\%) were married compared to the males (approximately 7\%). Nearly half (48\%) of the students rated themselves as coming from families that were either not well off or were poor. Less than $1 \%$ of the students recorded their academic performance as not satisfactory. The percentage of those who had

Table 1 Sociodemographic characteristics

\begin{tabular}{|c|c|c|c|c|c|c|}
\hline & \multicolumn{2}{|c|}{ Overall } & \multicolumn{2}{|c|}{ Male } & \multicolumn{2}{|c|}{ Female } \\
\hline & $N$ & $\%$ & $N$ & $\%$ & $N$ & $\%$ \\
\hline All & 923 & & 525 & & 365 & \\
\hline \multicolumn{7}{|l|}{ Age } \\
\hline$<20$ & 200 & 23.39 & 122 & 24.11 & 78 & 22.35 \\
\hline $20-24$ & 515 & 60.23 & 311 & 61.46 & 204 & 58.45 \\
\hline $25-29$ & 84 & 9.82 & 49 & 9.68 & 35 & 10.03 \\
\hline 30 and above & 56 & 6.54 & 24 & 4.74 & 32 & 9.17 \\
\hline \multicolumn{7}{|l|}{ Year of study } \\
\hline First & 185 & 21.17 & 128 & 25.40 & 56 & 15.60 \\
\hline Second & 256 & 29.29 & 143 & 28.37 & 111 & 30.92 \\
\hline Third & 195 & 22.31 & 107 & 21.23 & 85 & 23.68 \\
\hline Fourth, fifth and sixth & 238 & 27.22 & 126 & 25.00 & 107 & 29.81 \\
\hline \multicolumn{7}{|l|}{ College } \\
\hline CAVS & 66 & 7.17 & 41 & 7.69 & 25 & 6.70 \\
\hline CAE & 149 & 16.18 & 101 & 18.95 & 45 & 12.06 \\
\hline CBPS & 150 & 16.28 & 93 & 17.45 & 57 & 15.28 \\
\hline CEES & 193 & 20.95 & 109 & 20.45 & 81 & 21.72 \\
\hline $\mathrm{CHS}$ & 30 & 3.25 & 12 & 2.25 & 18 & 4.83 \\
\hline CHSS & 333 & 36.16 & 177 & 33.21 & 147 & 39.41 \\
\hline
\end{tabular}

Marital status

Married

$\begin{array}{llllll}90 & 9.96 & 35 & 6.67 & 54 & 14.79\end{array}$

Single

$\begin{array}{llllll}813 & 90.03 & 490 & 93.33 & 311 & 85.21\end{array}$

Religion

Christian

$\begin{array}{llllll}752 & 82.28 & 439 & 82.67 & 303 & 82.34\end{array}$

Muslim

$\begin{array}{llllll}61 & 6.67 & 34 & 6.40 & 24 & 6.52\end{array}$

Other

$\begin{array}{llllll}101 & 11.05 & 58 & 10.92 & 41 & 11.14\end{array}$

Residence

On campus

$\begin{array}{llllll}616 & 67.99 & 387 & 73.71 & 219 & 60\end{array}$

Off campus (on your own or with parents/guardians)

$\begin{array}{llllll}290 & 32.01 & 138 & 26.28 & 146 & 40.11\end{array}$

Family background

Wealthy/Quite well off

$\begin{array}{llllll}469 & 52.00 & 251 & 47.68 & 207 & 56.87\end{array}$

Not very well off/Quite poor

$\begin{array}{llllll}433 & 48.0 & 271 & 51.91 & 157 & 43.13\end{array}$

Academic performance

Excellent/Nery good

$\begin{array}{llllll}449 & 57.93 & 260 & 57.14 & 182 & 58.30\end{array}$

Good/Satisfactory

$\begin{array}{llllll}320 & 41.29 & 191 & 41.97 & 125 & 40.46\end{array}$

Not satisfactory $\begin{array}{llllll}6 & 0.77 & 4 & 0.88 & 2 & 0.65\end{array}$ 
Table 2 Prevalence of depressive symptoms

\begin{tabular}{|c|c|c|c|}
\hline & Moderate (\%) & Severe (\%) & Chi-square ( $P$ value) \\
\hline All & $35.71(30.03-36.20)$ & $5.62(3.90-6.89)$ & \\
\hline \multicolumn{4}{|l|}{ Social demographic } \\
\hline \multicolumn{4}{|l|}{ Age } \\
\hline$<20$ & $30.65(24.22-37.89)$ & $6.45(3.53-11.26)$ & \multirow[t]{4}{*}{0.0933} \\
\hline $20-24$ & $37.01(32.71-41.51)$ & $5.82(3.97-8.40)$ & \\
\hline $25-29$ & 27.50 (18.39-38.80) & $6.25(2.32-14.61)$ & \\
\hline 30 and above & $50.94(37.00-64.75)$ & $1.89(0.00-11.38)$ & \\
\hline \multicolumn{4}{|l|}{ Gender } \\
\hline Male & 33.54 (29.39-37.96) & 5.35 (3.59-7.84) & \multirow[t]{2}{*}{0.2598} \\
\hline Female & $39.03(33.94-44.37)$ & $5.13(3.16-8.13)$ & \\
\hline \multicolumn{4}{|l|}{ Year of study } \\
\hline First & $36.26(29.15-43.98)$ & $7.60(4.28-12.92)$ & \multirow[t]{4}{*}{0.2598} \\
\hline Second & $35.74(29.69-42.27)$ & $4.26(2.18-7.92)$ & \\
\hline Third & $38.33(31.28-45.89)$ & $5.56(2.85-10.26)$ & \\
\hline Fourth, fifth and sixth & $33.63(27.54-40.29)$ & $4.48(2.29-8.33)$ & \\
\hline \multicolumn{4}{|l|}{ College } \\
\hline CAVS & $35.00(23.44-48.48)$ & $6.67(2.16-17.00)$ & \multirow[t]{6}{*}{0.0745} \\
\hline CAE & $38.24(30.15-46.99)$ & $6.62(3.26-12.55)$ & \\
\hline CBPS & $34.33(26.48-43.09)$ & $5.22(2.31-10.87)$ & \\
\hline CEES & $42.62(35.42-50.14)$ & $2.73(1.01-6.60)$ & \\
\hline $\mathrm{CHS}$ & $14.81(4.86-34.61)$ & 0.00 & \\
\hline CHSS & $33.33(28.18-38.90)$ & $7.37(4.83-11.00)$ & \\
\hline \multicolumn{4}{|l|}{ Marital status } \\
\hline Married & $37.21(27.22-48.35)$ & $4.65(1.50-12.13)$ & \multirow[t]{2}{*}{0.9073} \\
\hline Single & $35.56(32.14-39.13)$ & $5.61(4.12-7.58)$ & \\
\hline \multicolumn{4}{|l|}{ Religion } \\
\hline Christian & $36.55(32.98-40.26)$ & $5.04(3.58-7.00)$ & \multirow[t]{3}{*}{0.3581} \\
\hline Muslim & 29.09 (18.02-43.09) & 7.27 (2.36-18.43) & \\
\hline Other & $33.68(24.51-44.20)$ & $9.47(4.69-17.67)$ & \\
\hline \multicolumn{4}{|l|}{ Residence } \\
\hline On campus & 35.27 (31.37-39.38) & $6.70(2.36-18.43)$ & \multirow[t]{2}{*}{0.0833} \\
\hline Off campus (on your own or with parents and guardians) & $35.93(30.26-42.00)$ & $2.96(1.38-5.98)$ & \\
\hline \multicolumn{4}{|l|}{ Family background } \\
\hline Wealthy/Quite well off & $33.72(29.30-38.43)$ & $2.56(1.35-4.67)$ & \multirow[t]{2}{*}{$<0.0001$} \\
\hline Not very well off/Quite poor & $37.44(32.75-42.37)$ & $8.87(6.37-12.17)$ & \\
\hline \multicolumn{4}{|l|}{ Academic performance } \\
\hline Excellent/Very good & $37.23(32.62-42.08)$ & $5.97(3.98-8.79)$ & \multirow[t]{3}{*}{0.1754} \\
\hline Good/Satisfactory & $30.17(25.06-35.81)$ & $5.76(3.50-9.24)$ & \\
\hline Not satisfactory & $50.0(18.76-81.23)$ & $16.67(0.87-63.52)$ & \\
\hline \multicolumn{4}{|l|}{ Alcohol usage } \\
\hline Alcohol use & $38.9(33.78-44.28)$ & $5.76(3.65-8.90)$ & \multirow[t]{2}{*}{0.2473} \\
\hline No Alcohol use & $33.53(29.46-37.85)$ & $5.52(3.78-7.98)$ & \\
\hline
\end{tabular}

Binge drinking 
Table 2 Prevalence of depressive symptoms (Continued)

\begin{tabular}{|c|c|c|c|}
\hline Binge drinking & $41.11(33.92-48.69)$ & $6.11(3.24-10.95)$ & 0.3160 \\
\hline Non-binge drinking & $35.90(27.39-45.35)$ & $3.42(1.10-9.04)$ & \\
\hline \multicolumn{4}{|l|}{ Tobacco usage } \\
\hline Tobacco use & $37.63(27.97-48.33)$ & $13.98(7.94-23.08)$ & 0.0004 \\
\hline Non-tobacco use & $33.83(30.08-37.80)$ & $4.50(3.04-6.56)$ & \\
\hline \multicolumn{4}{|l|}{ Sexual behaviour } \\
\hline \multicolumn{4}{|l|}{ Number of partners for past 12 months } \\
\hline None or 1 & $34.15(30.29-38.24)$ & $4.40(2.93-6.52)$ & 0.0195 \\
\hline$\geq 2$ & $38.81(33.18-44.75)$ & $8.04(5.28-11.98)$ & \\
\hline Consistent use of condom with partner & $32.78(28.37-37.51)$ & $6.84(4.71-9.79)$ & 0.0967 \\
\hline Non-consistent use & $38.60(34.01-43.41)$ & $4.42(2.76-6.94)$ & \\
\hline Sex after drinking past 3 months & $46.75(39.09-54.55)$ & $5.33(2.22-9.43)$ & 0.0066 \\
\hline No sex after drinking past 3 months & $33.50(29.76-37.46)$ & $4.73(3.73-7.52)$ & \\
\hline Ever diagnosed with STI & $50.65(39.10-62.13)$ & $6.49(2.42-15.15)$ & 0.0101 \\
\hline Never diagnosed with STI & $34.26(30.82-37.87)$ & $5.13(3.69-7.07)$ & \\
\hline Ever diagnosed with HIV & $57.69(37.19-76.03)$ & $19.23(7.31-39.98)$ & $<0.0001$ \\
\hline Never diagnosed with HIV & $34.58(31.25-38.05)$ & $4.88(3.52-6.71)$ & \\
\hline Ever been hit by a sexual partner & $56.67(43.30-69.18)$ & $11.67(5.21-23.18)$ & $<0.0001$ \\
\hline Never been hit by sexual partner & $34.05(30.67-37.59)$ & $4.67(3.34-6.53)$ & \\
\hline Ever been forced to have sex & $65.12(54.00-74.87)$ & $9.30(4.39-18.00)$ & $<0.0001$ \\
\hline Never been forced to have sex & $32.28(30.11-37.10)$ & $4.83(3.43-6.72)$ & \\
\hline Physically abused as a child & $43.24(31.94-55.24)$ & $13.51(7.02-23.91)$ & 0.0007 \\
\hline Never physically abused as a child & $34.83(31.41-38.40)$ & $4.63(3.27-6.47)$ & \\
\hline Sexually abused as a child & $53.06(38.42-67.22)$ & $8.16(2.65-20.48)$ & 0.0122 \\
\hline Never sexually abused as a child & $34.56(31.20-38.09)$ & $5.15(3.73-7.01)$ & \\
\hline
\end{tabular}

ever been diagnosed with sexually transmitted disease was 9.71\% (males 8.65\%; females 11.01\%); and for HIV 3.04\% (males 2.02\%; females 4.05\%).

\section{Depression}

The prevalence of depression among the students is shown in Table 2. Overall, 41.33\% of the students scored above the cut-off point of 10 on the CES-D 10 scale, with 35.71 having moderate symptoms and $5.62 \%$ having severe depressive symptoms. Proportionately, more females had depressive symptoms compared to males but the difference was not statistically significant. Similarly, no statistically significant difference was noted among the different age groups although approximately half of those in the age group of 30 years and above were reported to have mild-moderate symptoms of depression. The rates of depressive symptoms among those who reported binge drinking were high (though not statistically significant) compared to that of those who did not report binge drinking. However, tobacco use was significantly associated with depressive symptoms.
Other factors associated with high levels of depressive symptoms included having a positive history of HIV or STI infection. Those who reported traumatic events such as having been hit by a sexual partner, having been forced to have sex and having been physically abused as a child also reported significantly higher levels of depressive symptoms compared to those who did not report such events.

\section{Association with risky sexual behaviour}

The two factors defining risky sexual behaviour were having more than two sexual partners within the past 12 months and inconsistent condom use. The former was reported by $30 \%$ of the students. Inconsistent condom use was reported by $27.48 \%$ of the students (males 26.74 and females 28.75). One-fifth of the students reported engaging in sex after drinking. In multivariable-bivariate logistic regression, being older, having depressive symptoms, alcohol use/binge drinking, tobacco use, sex after drinking, previous diagnosis of STI and sexually abused as a child were significantly associated with having multiple partners. Further, younger age, being female, tobacco use 
Table 3 Associations between risky sexual behaviour (multiple sexual partners, inconsistent condom use) and mental health covariates

\begin{tabular}{|c|c|c|c|c|}
\hline & \multicolumn{2}{|c|}{ Multiple sexual partners } & \multicolumn{2}{|c|}{ Inconsistent condom use } \\
\hline & $\begin{array}{l}\text { Unadjusted odds } \\
\text { Ratio ( } 95 \% \text { C.I) }\end{array}$ & $\begin{array}{l}\text { Adjusted odds } \\
\text { ratio (95\% C.I) }\end{array}$ & $\begin{array}{l}\text { Unadjusted odds } \\
\text { ratio }(95 \% \text { C.I) }\end{array}$ & $\begin{array}{l}\text { Adjusted odds } \\
\text { ratio (95\% C.I) }\end{array}$ \\
\hline \multicolumn{5}{|l|}{ Social demographic } \\
\hline Age & $0.95(0.92-0.99)^{* *}$ & $1.12(1.00-1.28)^{*}$ & $0.85(0.80-0.89)^{* * *}$ & $0.90(0.83-0.97)^{* * *}$ \\
\hline \multicolumn{5}{|l|}{ Gender } \\
\hline \multicolumn{5}{|l|}{ Female $^{a}$} \\
\hline Male & $1.74(1.30-2.33)^{* * *}$ & $4.10(1.72-10.43)$ & $0.87(0.66-0.92)^{*}$ & $0.99(0.67-1.47)^{* * *}$ \\
\hline \multicolumn{5}{|l|}{ Year of study } \\
\hline \multicolumn{5}{|l|}{ First $^{a}$} \\
\hline Second & $1.36(0.92-2.03)$ & $3.20(0.93-11.69)$ & $0.89(0.61-1.31)$ & - \\
\hline Third & $1.26(0.82-1.93)$ & $2.18(0.58-8.56)$ & $0.74(0.49-1.12)$ & - \\
\hline Fourth, fifth and sixth & $1.76(1.17-2.67)^{* *}$ & $3.05(0.84-11.61)$ & $0.80(0.54-1.19)$ & - \\
\hline \multicolumn{5}{|l|}{ College } \\
\hline \multicolumn{5}{|l|}{ CAVS $^{a}$} \\
\hline CAE & $0.87(0.43-1.67)$ & $0.29(0.04-2.06)$ & $0.61(0.33-1.11)$ & $1.22(0.52-2.86)$ \\
\hline CBPS & $0.54(0.27-1.03)$ & $0.99(0.12-7.37)$ & $0.40(0.22-0.73)^{* *}$ & $0.55(0.23-1.31)$ \\
\hline CEES & $0.36(0.19-0.67)^{* *}$ & $0.52(0.34-0.62)^{*}$ & $0.24(0.13-0.43)^{* * *}$ & $0.46(0.18-1.13)$ \\
\hline $\mathrm{CHS}$ & $0.76(0.29-2.05)$ & $0.31(0.03-2.55)$ & $1.28(0.51-3.36)$ & $2.71(0.76-10.46)$ \\
\hline CHSS & $0.73(0.39-1.33)$ & $0.67(0.05-10.70)$ & $0.63(0.36-1.08)$ & $0.76(0.34-1.66)$ \\
\hline \multicolumn{5}{|l|}{ Marital status } \\
\hline \multicolumn{5}{|l|}{ Married $^{\mathrm{a}}$} \\
\hline Single & $1.08(0.66-1.75)$ & - & $1.56(0.98-1.92)$ & - \\
\hline \multicolumn{5}{|l|}{ Religion } \\
\hline \multicolumn{5}{|l|}{ Christian $^{a}$} \\
\hline Muslim & $1.53(0.85-2.90)$ & - & $0.66(0.38-1.14)$ & - \\
\hline Other & $1.16(0.75-1.85)$ & - & $0.60(0.39-1.12)$ & - \\
\hline \multicolumn{5}{|l|}{ Residence } \\
\hline \multicolumn{5}{|l|}{ On campus ${ }^{\mathrm{a}}$} \\
\hline Off campus (on your own or with parents and guardians) & $1.18(0.87-1.60)$ & - & $0.47(0.35-1.42)$ & - \\
\hline \multicolumn{5}{|l|}{ Family background } \\
\hline \multicolumn{5}{|l|}{ Wealthy/Quite well offa } \\
\hline Not very well off/Quite poor & $1.10(0.83-1.45)$ & - & $1.05(0.80-1.37)$ & - \\
\hline \multicolumn{5}{|l|}{ Academic performance } \\
\hline \multicolumn{5}{|l|}{ Excellent/Nery good ${ }^{\mathrm{a}}$} \\
\hline Good/Satisfactory & $0.94(0.70-1.28)$ & - & $1.49(0.07-1.99)$ & - \\
\hline Not satisfactory & $1.03(0.20-7.50)$ & - & $0.56(0.08-2.90)$ & - \\
\hline \multicolumn{5}{|l|}{ Depression } \\
\hline \multicolumn{5}{|l|}{ No depression ${ }^{a}$} \\
\hline Moderate & $1.78(1.57-2.05)$ & $2.76(1.83-3.11)^{* *}$ & $1.80(1.60-2.06)^{*}$ & $0.92(0.61-1.39)$ \\
\hline Severe & $1.51(1.27-1.95)^{*}$ & $2.01(1.50-3.22)^{* *}$ & $1.38(0.75-2.59)$ & $1.18(0.47-2.97)$ \\
\hline Alcohol use (reference $=$ No) & $2.07(1.57-2.75)^{* * *}$ & $3.68(2.64-4.13)^{* * *}$ & $1.55(1.18-2.02)^{* *}$ & $1.98(0.64-2.52)$ \\
\hline Binge drinking $($ reference $=$ No) & $1.82(1.14-2.89)^{*}$ & $2.12(1.85-2.46)^{* *}$ & $1.18(0.74-1.89)$ & - \\
\hline Tobacco use (reference = No) & $3.36(2.18-5.22)^{* * *}$ & $2.26(2.02-2.39)^{* * *}$ & $1.97(1.27-3.14)^{* *}$ & $1.78(1.44-2.87)^{* *}$ \\
\hline
\end{tabular}

Sexual behaviour 
Table 3 Associations between risky sexual behaviour (multiple sexual partners, inconsistent condom use) and mental health covariates (Continued)

\begin{tabular}{lllll}
\hline Sex after drinking past 3 months (reference = No) & $5.10(3.58-7.33)^{* * *}$ & $3.94(1.62-10.17)^{*}$ & $3.81(2.59-5.72)^{* * *}$ & $3.77(0.22-7.04)$ \\
Ever diagnosed with STI (reference $=$ No) & $3.70(2.32-5.99)^{* * *}$ & $6.48(1.36-20.33)^{*}$ & $3.60(2.12-6.44)^{* * *}$ & $2.99(1.21-4.50)^{*}$ \\
Ever diagnosed with HIV (reference = No) & $2.25(0.97-5.25)$ & & $2.53(1.04-7.09)$ & - \\
Ever been hit by a sexual partner (reference = No) & $2.33(1.32-3.77)^{* *}$ & $2.35(0.44-3.77)$ & $2.39(0.33-4.36)$ & $2.13(0.11-6.23)$ \\
Ever been forced to have sex (reference $=$ No) & $1.74(1.11-2.73)^{*}$ & $3.56(0.92-4.61)$ & $1.68(1.07-2.69)^{*}$ & $5.29(0.43-17.50)$ \\
Physically abused as a child (reference $=$ No) & $1.04(0.63-1.67)$ & - & $1.01(0.64-1.61)$ & - \\
Sexually abused as a child (reference $=$ No) & $1.78(0.98-3.20)$ & $1.87(1.52-2.11)^{* *}$ & $2.20(1.19-4.30)^{*}$ & $1.81(0.92-3.21)$ \\
\hline
\end{tabular}

Based on bivariate logistic regression estimates.

${ }^{*} P<.05 ; * * P<.01 ; * * * P<.001$

${ }^{a}$ Reference level.

C.I = confidence level.

and previous diagnosis of STI were significantly associated with inconsistent condom use (Table 3).

\section{Discussion}

The overall prevalence rate of HIV in this sample was $3.04 \%$ (males $2.02 \%$ and females $4.05 \%$ ). This is lower than the Kenyan national average for a comparable age group. However, the study shows that a considerable number of students engage in risky sexual behaviour. Approximately $30 \%$ reported having had multiple sexual partners, and one-fifth of the students had engaged in sex after drinking. More than one quarter of both males and females reported non-use of condoms with sexual partners, yet $36 \%$ of the males and $21 \%$ of the females had more than two sex partners in the proceeding 12 months. These findings are comparable to other studies among university students in the region. A local study among Maseno University students in Western Kenya reported that $25.6 \%$ of the students engaged in sex while intoxicated with alcohol [20]. Similar findings have been also been reported from Ugandan university students where risky sexual behaviour was linked to drinking and high STI levels [21].

HIV transmission in Kenya is mainly through heterosexual sex, and efforts to decrease the HIV transmission rates in Kenya have concentrated mainly on reproductive health with an emphasis on safe sexual practices such as condom use, voluntary counselling and testing and more recently voluntary medical male circumcision [22]. While these interventions have had some effect and there has been a general decline in HIV prevalence rates among the age group 15-49 from 1990s to 2008, there are concerns that the prevalence rate has since stabilised and that infection rates among the youth account for $21 \%$ of all new infections [3]. To sustain the gains made, a rate of zero infections should be the aim. It is therefore essential to explore all the correlates of risky sexual behaviour and formulate appropriate interventions.
Risky sexual behaviour is positively linked to depression as has been shown in studies from other student groups $[13,14]$. Similarly in this study, having depressive symptoms was associated with having multiple partners. It could be that depressive feelings lead to risky sexual behaviour. Alternatively, risky sexual behaviour, being forced to have sex and being hit by a sexual partner, factors which are high in this sample, are the causes of high depressive symptoms. Sexual coercion was also found to be common among Ugandan university students, having affected nearly one-third of those sampled and was associated with subsequent risky sexual behaviour [23]. Further studies are needed to confirm these links particularly in areas with high HIV prevalence rates.

Given the low number of mental health workers in Kenya, it is possible that many of those with moderate to severe depressive symptoms that would need some intervention may go untreated. It is therefore important that workers in reproductive health or general health facilities be made aware of the links between STI risky HIV behaviour and poor mental health. Students who present to the student health services with STIs, history of alcohol use and physical abuse should be screened for depressive illnesses. Programmes that address issues of HIV, for example awareness campaigns, should also include discussions on identification of depression.

\section{Limitations}

Since this was a cross-sectional study dependent and was dependent upon self report of symptoms, there could have been errors related to inaccurate reporting. The university population sampled in this study also differs from the youth population in education and exposure to different cultures and social pressures. These factors could limit the generalisability of the results. However, this is a national university that admits students from all over Kenya and so the findings may be applicable to students from other developing countries in the region. 


\section{Conclusions}

HIV rates are lower in the students' population compared to the national average, but the prevalence of risky sexual behaviour is high and positively linked to depression. Interventions aimed at HIV prevention should be integrated with mental health assessment and treatment.

\section{Competing interests}

The authors declare that they have no competing interests.

\section{Authors' contributions}

CJO designed the study, analysed the data and drafted the manuscript. RO contributed to the draft. KP and SP conceptualised the study. LOM conducted the sampling and analysed the data. All authors read and approved the final manuscript.

\section{Acknowledgements}

We thank the students who participated in the study, the administration of the University of Nairobi, especially Registrar Academics for facilitating the study; Cherryl Ojjerro, Rachel Maina, Eston Nyakiya, Julius Oduor and Amelia Awoko who assisted with the data collection.

\section{Author details}

${ }^{1}$ Department of Psychiatry, University of Nairobi, P.O. Box 19676, 00202 Nairobi, Kenya. ${ }^{2}$ ASEAN Institute for Health Development, Mahidol University, Nakhon Pathom, Thailand. ${ }^{3}$ Human Sciences Research Council, Pretoria, South Africa. ${ }^{4}$ University of Limpopo, Turfloop Campus, Polokwane, South Africa. ${ }^{5}$ Kenya Medical Research Institute, Wellcome Trust, Nairobi, Kenya.

Received: 17 April 2014 Accepted: 24 March 2015

Published online: 11 April 2015

\section{References}

1. Kimanga DO, Ogola S, Umuro M, Nganga A, Kimondo L, Mureithi P, et al Prevalence and incidence of HIV infection, trends, and risk factors among persons aged 15-64 years in Kenya: results from a nationally representative study. J Acquired Immune Deficiency Syndrome. 2014.

2. Oluoch T, Mohammed I, Bunnell R, Kaiser R, Kim AA, Gichangi A, et al. Correlates of HIV infection among sexually active adults in Kenya: a national population-based survey. Open AIDS J. 2011;5:125-34.

3. National AIDS and STI Control Programme. Kenya HIV estimates. Nairobi: Government of Kenya; 2014.

4. Heere GA, Mandeya A, Jemmott JB, Chiruka RT, Marange CS, Batidzirai JM, et al. Multiple partners and condom use among students at a South African university. J Evid Based Soc Work. 2014;11:437-44.

5. Liu Z, Wei P, Huang M, Liu YB, Li L, Gong X, et al. Determinants of consistent condom use among college students in China: application of the information-motivation-behavior skills (IMB). Plos One. 2014;9(9):e108976.

6. Ngatu NR, Hirota R, Eitoku M, Muzembo BA, Nishimori M, Kuramochi M, et al. Perception of the risk of sexual transmission of HIV among Congolese and Japanese university students. Environ Health Prev Med. 2012;12(2):139-46.

7. Rahamefy $\mathrm{OH}$, Rivard M, Ravaoarinoro M, Ranaivoharisoa $L$, Rasamindrakotroka AJ, Morisset R. Sexual behaviour and condom use among university students in Madagascar. SAHARA J. 2008;5(1):28-35.

8. Doyle AM, Mavedzenge SN, Plummer ML, Ross DA. The sexual behaviour of adolescents in sub-Saharan Africa: patterns and trends from national surveys. Trop Med Int Health. 2012;17(7):796-807.

9. Onipede W. Mass media and sexual health behaviour of college students in Nigeria: a study of Lagos State University. East Afr J Public Health. 2009;6(3):303-8

10. Mmari K, Blum RW. Risk and protective factors that affect adolescent reproductive health in developing countries: a structured literature review. Glob Public Health. 2009:4:350-66.

11. Okonkwo PI, Fatusi AO, llika AL. Perception of peers' behaviour regarding sexual health decision making among female undergraduates in Anambra State, Nigeria. Afr Health Sci. 2005;5(2):107-13.

12. Rubin AG, Gold MA, Primack BA. Associations between depressive symptoms and sexual risk behaviour in a diverse sample of female adolescents. J Paediatr Adolesc Gynaecol. 2009;22:306-12.
13. Argadh A, Cantor-Graae E, Ostergren PO. Youth, sexual risk-taking behavior, and mental health: a study of university students in Uganda. Int J Behav Med. 2012;19(2):208-16.

14. Nduna M, Jewkes RK, Dunkle KL, Shai N, Colman I. Associations between depressive symptoms, sexual behaviour and relationship characteristics: a prospective cohort study of young women and men in Eastern Cape, South Africa. J Int AIDS Soc. 2010;13:44.

15. Peltzer K, Pengpid S, Tiembre I. Mental health, childhood abuse and HIV sexual risk behaviour among university students in Ivory Coast. Ann Gen Psychiatr. 2013;12:18.

16. University of Nairobi. University population. 2013

17. Andreasen EM, Malmgren JA, Carter WB, Patrick DL. Screening for depression in well adults: evaluation of a short form of the CES-D (Center for Epidemiological Studies Depression Scale). Am J Prev Med. 1994;10(2):77-84

18. Mulrow CD, Williams JWJ, Gerety MB, Ramirez G, Montiel OM, Kerber C. Case-finding instruments for depression in primary care setting. Ann Intern Med. 1995;122(12):913-21.

19. Kilbourne A, Justice A, Rollman B, McGinnis K, Weissman S. Clinical importance of HIV and depressive symptoms among veterans with HIV infection. J Gen Intern Med. 2002;17(7):512-20.

20. Munyaka BS. Perceived benefits and barriers toward testing for sexually transmitted infections among undergraduate students at Maseno University Kisumu, Kenya. Nairobi: Jomo Kenyatta University of Agriculture and Technology; 2011.

21. Choudhry V, Agardh A, Stafstrom M, Ostergren P-O. Patterns of alcohol consumption and risky sexual behaviour: a cross-sectional study among Ugandan university students. BMC Public Health. 2014;14:128.

22. Centres for Disease Control and Prevention. Voluntary medical male circumcision-southern and eastern Africa, 2010-2012. MMWR Morb Mortal Wkly Rep. 2013;62(47):953-7.

23. Agardh A, Odberg-Pettersson K, Ostergren P-O. Experience of sexual coercion and risky sexual behaviour among university students. BMC Public Health. 2011;11:527.

\section{Submit your next manuscript to BioMed Central and take full advantage of:}

- Convenient online submission

- Thorough peer review

- No space constraints or color figure charges

- Immediate publication on acceptance

- Inclusion in PubMed, CAS, Scopus and Google Scholar

- Research which is freely available for redistribution

Submit your manuscript at www.biomedcentral.com/submit 